\title{
Multistate Structural Modeling and Voltage-Clamp Analysis of Epilepsy/Autism Mutation Kv10.2-R327H Demonstrate the Role of This Residue in Stabilizing the Channel Closed State
}

\author{
Yang Yang, ${ }^{1,2,3 *}$ Dmytro V. Vasylyev, ${ }^{1,2,3 *}$ Fadia Dib-Hajj, ${ }^{1,2,3}$ Krishna R. Veeramah, ${ }^{4}$ Michael F. Hammer, ${ }^{4}$ \\ Sulayman D. Dib-Hajj, ${ }^{1,2,3}$ and Stephen G. Waxman ${ }^{1,2,3}$ \\ ${ }^{1}$ Department of Neurology and ${ }^{2}$ Center for Neuroscience and Regeneration Research, Yale University School of Medicine, New Haven, Connecticut 06510, \\ ${ }^{3}$ Rehabilitation Research Center, Veterans Affairs Connecticut Healthcare System, West Haven, Connecticut 06516, and ${ }^{4}$ Arizona Research Laboratories \\ Division of Biotechnology, University of Arizona, Tucson, Arizona 85721
}

Voltage-gated potassium channel Kv10.2 (KCNH5) is expressed in the nervous system, but its functions and involvement in human disease are poorly understood. We studied a human Kv10.2 channel mutation $(\mathrm{R} 327 \mathrm{H})$ recently identified in a child with epileptic encephalopathy and autistic features. Using multistate structural modeling, we demonstrate that the Arg327 residue in the S4 helix of voltage-sensing domain has strong ionic interactions with negatively charged residues within the S1-S3 helices in the resting (closed) and early-activation state but not in the late-activation and fully-activated (open) state. The R327H mutation weakens ionic interactions between residue 327 and these negatively charged residues, thus favoring channel opening. Voltage-clamp analysis showed a strong hyperpolarizing $(\sim 70 \mathrm{mV})$ shift of voltage dependence of activation and an acceleration of activation. Our results demonstrate the critical role of the Arg327 residue in stabilizing the channel closed state and explicate for the first time the structural and functional change of a Kv10.2 channel mutation associated with neurological disease.

\section{Introduction}

The Kv10.2 channel (encoded by the KCNH5 gene) belongs to the ether-à-go-go (EAG) family within the voltage-gated potassium (Kv) channel superfamily (Saganich et al., 1999). EAG channel family members, including both Kv10.1 and Kv10.2, are overexpressed in cancer and have been suggested as tumor markers as well as cancer therapeutic targets (Camacho, 2006; Hemmerlein et al., 2006; Mello de Queiroz et al., 2006; Stühmer et al., 2006; Huang et al., 2012). Kv10.2 is natively expressed in the nervous system (Saganich et al., 1999; Ludwig et al., 2000; Ju and Wray, 2002; Schonherr et al., 2002); however, the functions of Kv10.2 in

Received May 29, 2013; revised Sept. 4, 2013; accepted Sept. 10, 2013.

Author contributions: Y.Y., D.V.V., S.D.D.-H., and S.G.W. designed research; Y.Y. and D.V.V. performed research; F.D.-H., K.R.V., and M.F.H. contributed unpublished reagents/analytic tools; Y.Y., D.V.V., and S.D.D.-H. analyzed data; Y.Y., D.V.V., S.D.D.-H., and S.G.W. wrote the paper.

*Y.Y. and D.V.V. contributed equally to this work.

The authors declare no competing financial interests.

This work was supported by the Medical Research Service and Rehabilitation Research Service, Department of Veterans Affairs (S.G.W.). Y.Y. is supported by Connecticut Stem Cell Research Grants Program. The Center for Neuroscience and Regeneration Research is a Collaboration of the Paralyzed Veterans of America with Yale University. We thank Dr. Mark Estacion, Dr. Chongyang Han, and Dr. Jianying Huang for valuable comments. We thank Dr. David E. Shaw and Dr. Morten Jensen of D. E. Shaw Research for providing coordinates of their molecular dynamics simulation results and helpful discussion.

Correspondence should be addressed to Dr. Stephen G. Waxman, Neuroscience and Regeneration Research Center, Veterans Affairs Connecticut Healthcare System, 950 Campbell Avenue, Building 34, West Haven, CT 06516. E-mail: stephen.waxman@yale.edu.

DOI:10.1523/JNEUROSCI.2307-13.2013

Copyright $\odot 2013$ the authors $\quad 0270-6474 / 13 / 3316586-08 \$ 15.00 / 0$ the nervous system and its involvement in human diseases other than cancer are not well understood (Wulff et al., 2009). Recently, we identified a human Kv10.2 channel mutation $(\mathrm{R} 327 \mathrm{H})$ in a child with epileptic encephalopathy with seizures intractable to medical therapy and autistic features via exome sequencing (Veeramah et al., 2013). To understand how this R327H mutation, which substitutes a single residue within the voltage-sensing helix S4, affects the structure and function of Kv10.2, we performed this structural and functional study.

The crystal structures of mammalian Kv channels in the open state have been determined (Long et al., 2007), and recently the transitions of $\mathrm{Kv}$ channel from the activated (open) state to resting (closed) state have been studied using long ( $\geq 200 \mu \mathrm{s})$ allatom molecular dynamic simulations (Jensen et al., 2012), providing six structure snapshots of the intermediate states during channel gating. Here, using multistate structural modeling, we constructed a Kv10.2 voltage-sensing domain (VSD) model containing the wild-type (WT) Arg327 or mutant His327 residue in all six states obtained from molecular dynamic simulations (Jensen et al., 2012) and provide evidence showing that the resting and early activation state of the channel are destabilized by R327H mutation. This dynamic model suggests that the Arg327 residue of WT Kv10.2 has strong ionic interactions with negatively charged residues within the $\mathrm{S} 1-\mathrm{S} 3$ helices in the resting state and states transiting into or out of the resting state but not in the activated state. The R327H mutation weakens the ionic interaction between residue 327 and negatively charged residues of 
S1-S3, thus favoring channel opening. Consistent with this prediction, voltage-clamp analysis revealed a remarkable hyperpolarizing shift in the voltage dependence of activation and an acceleration of activation. Together, our results demonstrate the role of the Arg327 residue in stabilizing the closed state of the channel and explicate, for the first time, the structural and functional change of a Kv10.2 channel mutation associated with neurological disease.

\section{Materials and Methods}

Structural modeling and residue interaction maps. The alignment between Kv10.2 and other Kv channels was generated with ClustalW2 and manually refined based on previous studies (Long et al., 2007; Pathak et al., 2007; Lee et al., 2009; Zhang et al., 2009). Six different states of Kv1.2/ Kv2.1 "paddle chimera" voltage-gated $\mathrm{K}^{+}$channel (Protein Data Bank identification number 2R9R) obtained in a molecular dynamics simulation were kindly provided by Dr. David E. Shaw, D. E. Shaw Research (New York, NY) (Jensen et al., 2012). Modeling of the S1-S4 VSD in six states was performed with SWISS-MODEL (Arnold et al., 2006; Bordoli et al., 2009) and refined as described previously (Yang et al., 2011, 2012, 2013). Models were further energy minimized, analyzed, and visualized in Molecular Operating Environment (MOE; Chemical Computing Group). Ligand and receptor interaction maps were constructed using MOE.

Plasmid. Kv10.2 cDNA was synthesized from human fetal brain total RNA (Clontech) using SuperscriptIII Reverse Transcriptase (Invitrogen). The PCR product was cloned into pGEMT-easy vector (Promega) and then subcloned into pCDNA3mod (Cummins et al., 2001). In a second step, an EcoRI-NotI fragment from pIRES2-EGFP (Clontech) was cloned into downstream of the stop codon of Kv10.2 to generate plasmid phKv10.2-IRES-EGFP. Sequencing of the insert and comparing it with the reference sequence NM_139318 confirmed a 988 aa open reading frame, including one variant (c. 2233G $>$ A; p. A745T) within the $\mathrm{C}$ terminus of the channel, which has been reported as a natural variant with a minor allele frequency (MAF) $=0.25$ (www.1000genomes.org).

Transfection of human embryonic kidney 293 cells. Human embryonic kidney 293 (HEK293) cells, 80\% confluent in a 24-well plate, were transfected with phKv10.2-IRES-EGFP $(1 \mu \mathrm{g} /$ well) using Optifect (Invitrogen). Transfected cells were incubated at $37^{\circ} \mathrm{C}$ in $5 \% \mathrm{CO}_{2}$ for $48 \mathrm{~h}$ before recording the non-inactivating outward rectifying $\mathrm{K}^{+}$currents produced by Kv10.2 channels (Ju and Wray, 2002; Schonherr et al., 2002) in cells with green fluorescence.

Electrophysiology. Current was recorded from HEK293 cells using the whole-cell voltage-clamp method. Pipette resistance was 1.3-2 $\mathrm{M} \Omega$ when filled with the intracellular solution (in $\mathrm{mm}$ ): $130 \mathrm{KCl}, 10$ EGTA, 10 HEPES, $1 \mathrm{MgCl} 2$, and 5.6 glucose, $\mathrm{pH}$ adjusted to 7.3 with $\mathrm{KOH}(287$ mOsm). The series resistance of $2-5 \mathrm{M} \Omega$ was compensated by $70 \%$. The extracellular solution contained the following (in $\mathrm{mM}$ ): $133 \mathrm{NaCl}, 3 \mathrm{KCl}$, $1 \mathrm{CaCl}_{2}, 1 \mathrm{MgCl}_{2}, 10$ HEPES, 104 -AP, and 5.6 glucose, $\mathrm{pH}$ adjusted to 7.3 with $\mathrm{HCl}(288 \mathrm{mOsm})$. Data were recorded using an Axopatch 200B amplifier, digitized by Digidata 1322A (Molecular Devices). Data were analyzed using pClamp 10 (Molecular Devices) and Origin 8.5 (OriginLab) software. Currents were evoked by $3 \mathrm{~s}$ test voltage steps ranging from -140 to $+50 \mathrm{mV}$ (in $10 \mathrm{mV}$ increments), followed by a 1-s-long step to $0 \mathrm{mV}$ to obtain $G / G_{\max }$ ratios, from a holding potential of -100 $\mathrm{mV} . G / G_{\max }$ was calculated for the respective test voltages as the ratio of the instantaneous tail current amplitude to the maximal amplitude of the instantaneous tail current. The rising phase, excluding an initial $10 \mathrm{~ms}$, of the current was approximated by a single exponential. The data are presented as means \pm SE. Data were evaluated with Student's $t$ test, and significant difference was accepted when $p<0.05$.

\section{Results}

\section{Multistate structural analysis}

$\mathrm{Kv}$ channels are membrane proteins that consist of six transmembrane segments, including S1-S4 as the VSD, a relative independent domain that transforms membrane potential changes into channel gating, and S5 and S6 as the pore-forming module (Fig. $1 A$ ). Functional $\mathrm{Kv}$ channels are tetramers assembled from four independent subunits.

Sequence analysis shows that Arg327 is located in the critical S4 helix of the VSD (Fig. 1A). Within the S4 helix of VSD, Arg327, together with Lys325, Arg329, and Arg331 (commonly known as $\mathrm{R}[\mathrm{K}] 1-\mathrm{R} 4)$, are positively charged residues that sense changes in the membrane potential and produce a conformational change of the VSD, which in turn controls channel gating (Fig. 1A). Mutation $\mathrm{R} 327 \mathrm{H}$, identified from a child with epilepsy and other neurological diseases (Veeramah et al., 2013), occurs at the critical R2 position. At physiological $\mathrm{pH}, \operatorname{Arg}(\mathrm{R})$ is a positively charged residue, and $\mathrm{His}(\mathrm{H})$ is predominantly neutral (with a relatively small proportion carrying positive charges). Because multiple negatively charged residues existed in $\mathrm{S} 0-\mathrm{S} 3$ helices (Fig. $1 B$ ), we hypothesized that Arg327 may form ionic interaction with these negatively charged residues in certain channel gating states, and mutation $\mathrm{R} 327 \mathrm{H}$ may disrupt the ionic interaction between residue 327 and negative charged residues, thus affecting channel gating. To test this hypothesis, we constructed a Kv10.2 VSD structural model based on the crystal structure of Kv1.2/Kv2.1 paddle chimera channel in its open state (Protein Data Bank identification number 2R9R). Our structural model of Kv10.2 VSD in its open state is shown in Figure $1 C$. Positively charged residues are labeled cyan (Arg327 are labeled gray), and negatively charged residues are labeled red (Fig. 1C). As can be seen in Figure $1 C$, the $\mathrm{S} 4$ helix of the Kv10.2 channel is in an "outward" position ("outward" means close to the extracellular space and "inward" means close to the intracellular space) in this activated state, and the Arg327 residue is not in contact with any negatively charged residues.

Because channel gating involves substantial conformational changes of the S1-S4 helix of the VSD, we tested the hypothesis that Arg327 may interact with negatively charged residues in other intermediate states during the channel gating process. Because the crystal structures of $\mathrm{Kv}$ channels in other gating states are not yet available, we used structural snapshots obtained in a recent all-atom level molecular dynamics simulation (Jensen et al., 2012) of the Kv1.2/Kv2.1 paddle chimera channel as templates. This molecular dynamics simulation reveals the transitions of $\mathrm{Kv}$ channel from activated to resting state (Jensen et al., 2012) and generated six structural snapshots [1, activated state (2R9R); 2, early deactivation state; 3 , late deactivation state; 4, resting state; 5 , early activation state; and 6 , late activation state]. These structural snapshots displayed asynchronous transitions of the four subunits (subunits A-D), all having identical amino acid sequences. We constructed Kv10.2 structural models based on all six states (multistate structural modeling) for our analysis. For clarity, only models based on subunit D in six states are shown in Figure $1 C-H$. Interestingly, we observed that the $\mathrm{S} 4$ helix moves from an outward to inward position relative to the S1-S3 helices when it transits from activated state to resting state (Fig. $1 C-F$ ) and moves from an inward to outward position when it transits from the resting state back to activated state (Fig. $1 F-H$ ). During this gating transition, the distances between Arg327 and negatively charged residues change dramatically (Fig. $1 C-H$ ).

To investigate the interaction between Arg327 and other residues in detail, we used Arg327 as a "ligand" in all these states to probe the surrounding residues as "receptors" in these structural models. By plotting the ligand-receptor interaction, we constructed an interaction map between Arg327 and surrounding residues (Fig. $2 A-F$, left panels). From the structural models and interaction maps, we observed that Arg327 does not interact with 
A

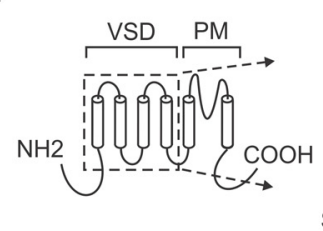

C

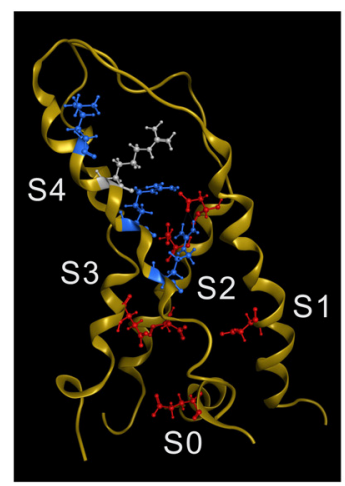

4

$H$

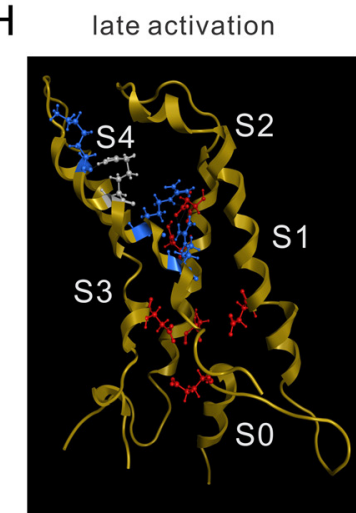

VSD

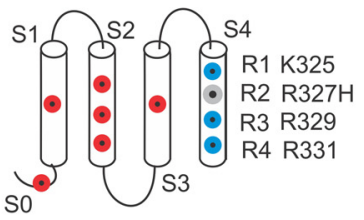

B

$$
\begin{gathered}
\text { E198 } \\
\text { S0- GSDILPQYKQEA } \\
\text { D218 } \\
\text { S1- YCAFKTTWDWVILILTFYTAIMVPY } \\
\text { D251 D255 D261 } \\
\text { S2- WLVLDSVVDIFLVDIVLNFHTTFV } \\
\text { D296 } \\
\text { S3- YLKTWFVIDLLSCLPYDIINAFENVD } \\
\text { R327H } \\
\text { S4- LFSSLKVVRLLRLGRVARKLDHYLE }
\end{gathered}
$$

\section{E late deactivation}
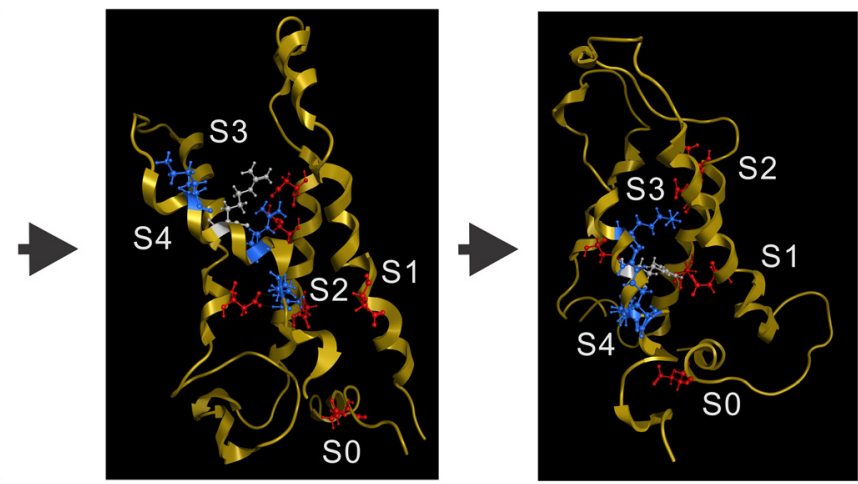

G

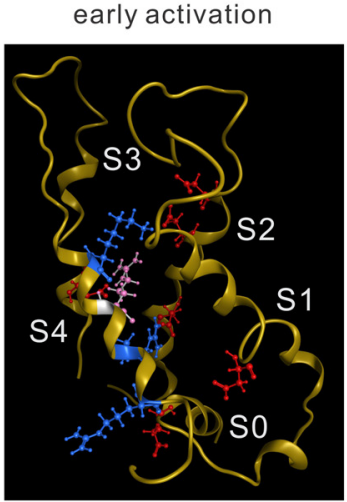

F
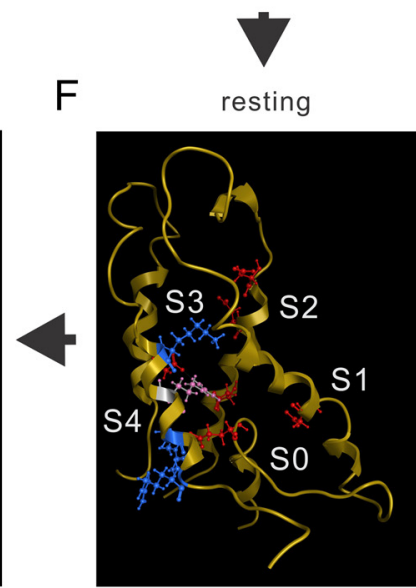

Figure 1. Structural modeling of Kv10.2 Arg327 in six states. A, Schematic of the human Kv10.2 channel. The boxed area is VSD, which is enlarged at the right. PM: Pore-forming module. Negatively charged residues are labeled red, and positively charged residues are labeled cyan. R327H mutation is labeled gray. $\boldsymbol{B}$, The amino acid sequence of the $\mathrm{SO}-\mathbf{S 4}$ helix is shown, highlighting the negatively and positively charged residues. $\mathbf{C}-\boldsymbol{H}$, Structural model of the Kv10.2 channel VSD in six different states. Negatively charged residues are shown in red and sticks, whereas positively charged residues are shown in cyan and sticks (Arg327 are shown in gray and sticks). Connecting loops between SO and S1, and S2 and S3 are omitted in some panels for clarity. C, Activated state; $\boldsymbol{D}$, early deactivation state; $\boldsymbol{E}$, late deactivation state; $\boldsymbol{F}$, resting state; $\boldsymbol{G}$, early activation state; $\boldsymbol{H}$, late activation state. Note that residue 327 moves from the outward position to the inward position from $\boldsymbol{C}$ toward $\boldsymbol{F}$, establishing interaction with negatively charged residues. Residue 327 moves from the inward position to the outward position from $\boldsymbol{F}$ to $\boldsymbol{C}$, attenuating the interaction with negatively charged residues.

any negatively charged residues in the activated state (Fig. $2 \mathrm{~A}$, left), but it interacts with Asp251 in the early deactivation state (Fig. 2B, left). When the channel enters the late deactivation state and the resting state, Arg327 interacts with two negatively charged residues (Asp218 and Asp261, Fig. 2C, left; Asp296 and Asp261, Fig. 2D, left, respectively). When the channel transits to an early activation state, Arg327 again only interacts with one negatively charged residue (Asp296; Fig. 2E, left) and loses all interaction with any negatively charged residues in the late activation state (Fig. $2 F$, left).

Compared with positively charged residue arginine, histidine residues are predominantly neutral at physiological $\mathrm{pH}$ and of smaller side chain size. Although it is difficult to predict the $\mathrm{pH}$ in the vicinity of $\mathrm{R} 327 \mathrm{H}$ within the folded protein and whether it changes during gating, it is reasonable to assume that, under physiological conditions, histidine residues are predominantly neutral (with a relatively small proportion carrying positive charges). Modeling of the $\mathrm{R} 327 \mathrm{H}$ mutation channel in all six states and construction of interaction maps showed that the $\mathrm{R} 327 \mathrm{H}$ mutation indeed impairs ionic interaction formation between residue 327 and negatively charged residues in S1-S3 (Fig. $2 A-F$, right panels). In the early deactivation state, the interaction between the mutated His327 residue and Asp251 still existed (Fig. $2 B$, right). However, interaction with negatively charged residues was not seen in the late deactivation state (Fig. $2 C$, right). In the resting state, the mutated His 327 residue lost its interaction with Asp261 and Asp296 but formed a new interaction with Glu198 (Fig. 2D, right). The mutated His327 residue still has interaction with Asp296 (Fig. 2E, right) in the early activation state but no interaction with negatively charged residues in the late activation state (Fig. 2F, right). Together, these data suggest that residue 327 contributes substantially to the stability of the Kv10.2 channel in 
A activated

B

Arg327 R327H Arg327 early deactivation

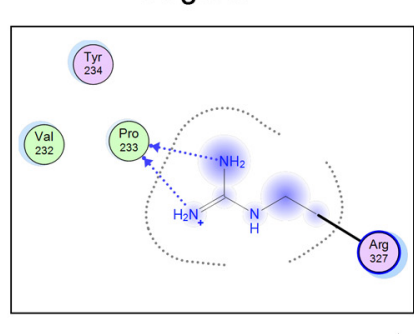

F late activation Arg327



E early activation
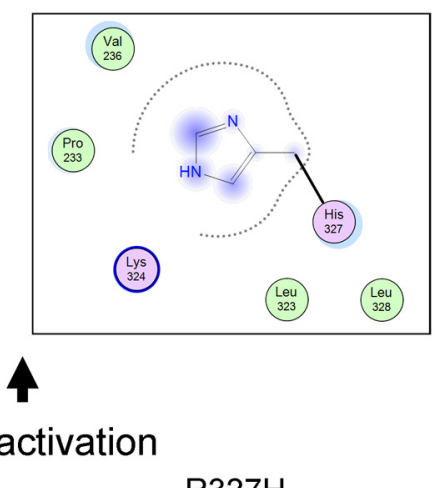

$\mathrm{R} 327 \mathrm{H}$

\section{C}

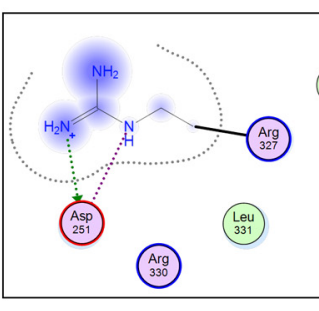

$\mathrm{R} 327 \mathrm{H}$

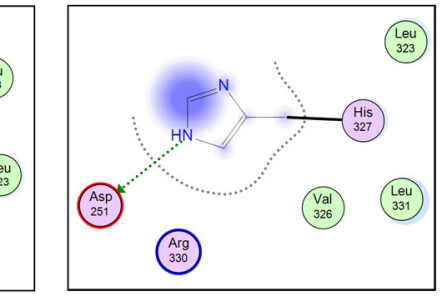

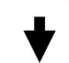

late deactivation

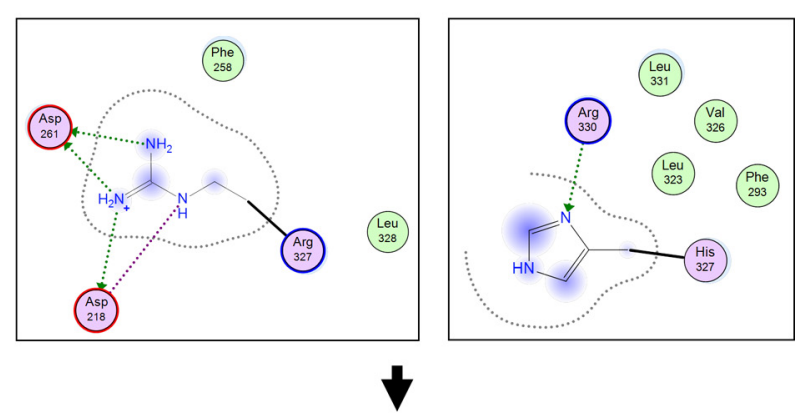

resting
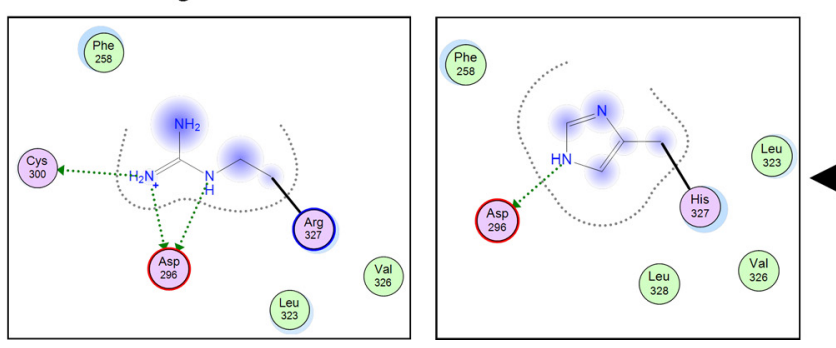

D

Arg327

$\mathrm{R} 327 \mathrm{H}$
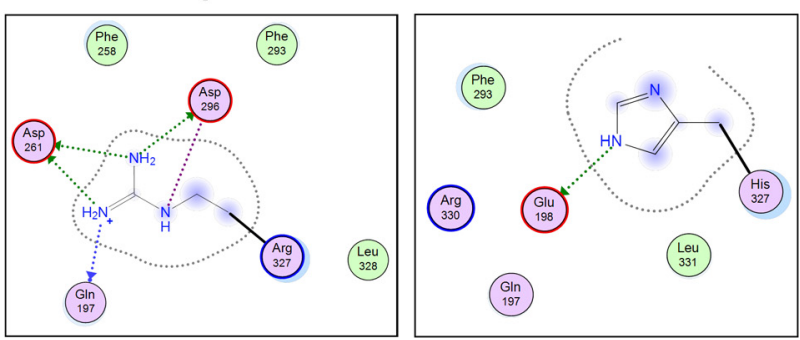

Figure 2. Interaction map of Arg327 and R327H mutation with surrounding residues. $\boldsymbol{A}$, Activated state; $\boldsymbol{B}$, early deactivation state; $\boldsymbol{C}$, late deactivation state; $\boldsymbol{D}$, resting state; $\boldsymbol{E}$, early activation state; $\boldsymbol{F}$, late activation state. Dashed arrows indicate residue interactions. Note that, in the $\mathrm{R} 327 \mathrm{H}$ mutation, the interactions between residue 327 and surrounding residues are markedly reduced in the resting state (and states transiting into or out of resting state).

its resting state via interacting with negatively charged residues. By mutating the predominantly positively charged arginine with the predominantly neutral histidine, the strong ionic interaction between residue 327 and negatively charged residues in the resting state (and states transiting into or out of resting state) is disrupted, resulting in a channel that can be more easily activated.

Because the molecular dynamic simulation of Kv1.2/Kv2.1 paddle chimera channel resulted in asynchronous conformational changes in the four subunits, we further explored the interactions between the Arg327 residue and negatively charged residues in all four subunits of Kv10.2 tetramer. Our results show that, in the activated state, the Arg327 residue does not interact with any negatively charged residues of the four subunits (Table 1). In the early deactivation state, the Arg327 residue interacts with Asp251 of subunit B and subunit D but not subunit A or subunit $C$ (Table 1 ). In the late deactivation state, the Arg327 residue interacts with Asp251 of subunit B and Asp218 and Asp261 of subunit D (Table 1) but not subunit A or subunit C. In the resting state, $\operatorname{Arg} 327$ residue interacts with negatively charged residues in all subunits (Asp296 of subunit A, Glu198 of subunit B, Asp261 of subunit C, and Asp261 an Asp296 of subunit D)
Table 1. Interactions between Arg327 and negatively charged residues in all four subunits of Kv10.2

\begin{tabular}{|c|c|c|c|c|c|}
\hline & \multirow[b]{2}{*}{ States } & \multicolumn{4}{|c|}{ Interactions between R327 and negatively charged residues } \\
\hline & & Subunit A & Subunit B & Subunit C & Subunit D \\
\hline State 1 & Activated & None & None & None & None \\
\hline State 2 & Early deactivation & None & Asp251 & None & Asp251 \\
\hline State 3 & Late deactivation & None & Asp251 & None & Asp218, Asp261 \\
\hline State 4 & Resting & Asp296 & Glu198 & Asp261 & Asp261, Asp296 \\
\hline State 5 & Early activation & Asp251, Asp255 & Asp261 & Asp251, Asp255 & Asp296 \\
\hline State 6 & Late activation & None & None & None & None \\
\hline
\end{tabular}

(Table 1). In the early activation state, the Arg327 residue again interacts with negatively charged residues of all subunits (Asp251 and Asp255 of subunit A, Asp261 of subunit B, Asp251 and Asp255 of subunit C, and Asp296 of subunit D) (Table 1). When the channel reaches the late activation state, Arg327 residue does not interact with any negatively charged residues of any subunits (Table 1). These data provide additional evidence that Arg327 has strong ionic interaction with negatively charged residues of all four subunits in Kv10.2 tetramer in resting state (and states transiting into or out of resting state). 
A

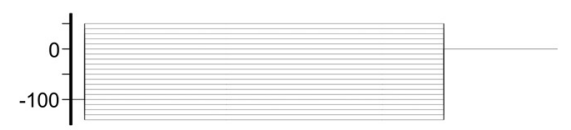

B

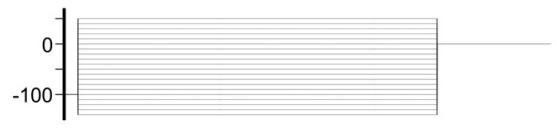

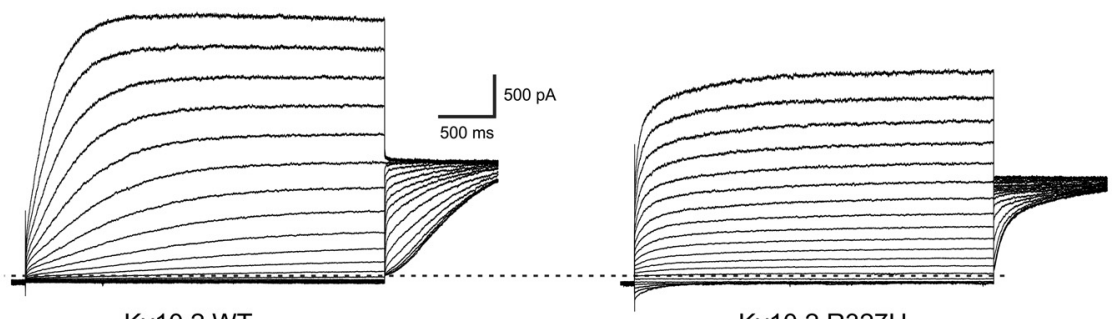

Kv10.2 WT

C

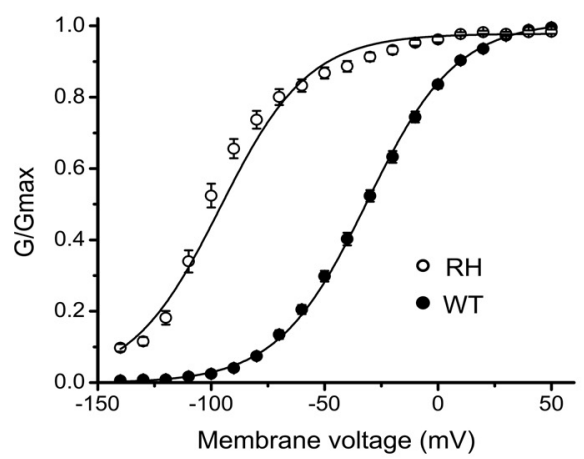

$\mathrm{E}$

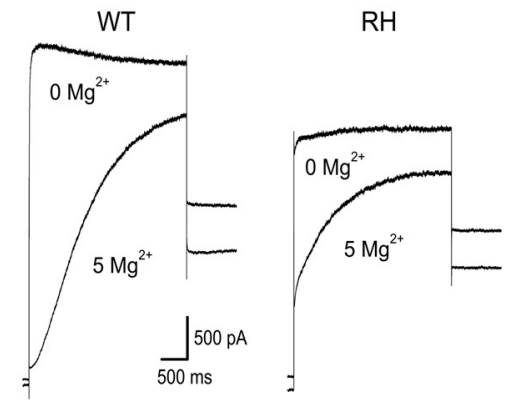

$\mathrm{D}$

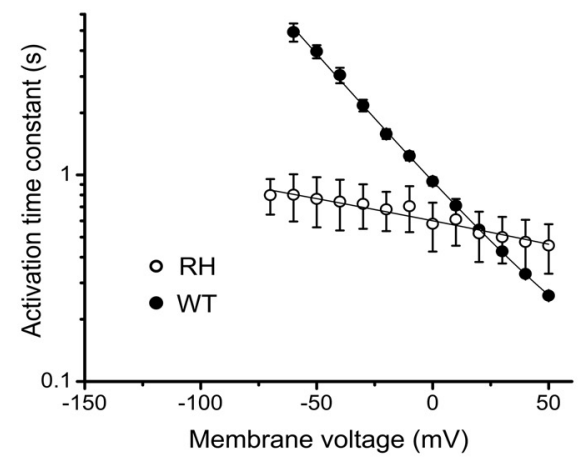

$\mathrm{F}$

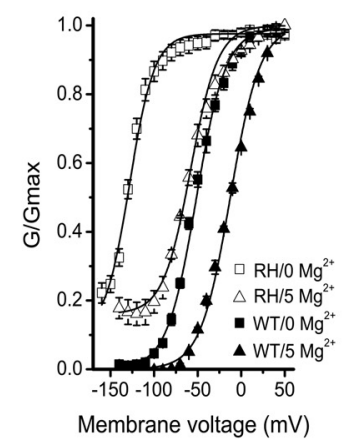

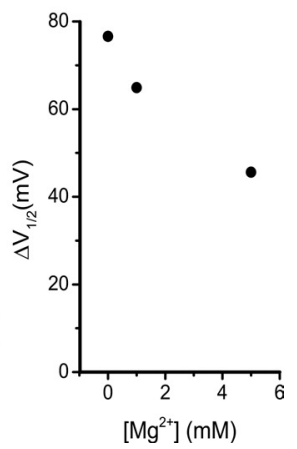

Figure 3. The R327H mutation results in a gain-of-function phenotype of the Kv10.2 channel. $\boldsymbol{A}, \boldsymbol{B}, \mathrm{WT}$ ( $\boldsymbol{A}$, bottom) and R327H ( $\boldsymbol{B}$, bottom) currents were evoked by 3-s-long test voltage steps ranging from -140 to $+50 \mathrm{mV}$ (in $10 \mathrm{mV}$ increments), followed by a 1-s-long step to $0 \mathrm{mV}$ to obtain $G / G_{\max }$ ratios, from a holding potential of $-100 \mathrm{mV}(\boldsymbol{A}, \boldsymbol{B}$, top). Dashed line represents 0 current. $C, G / G_{\max }$ was calculated for the respective test voltages as the ratio of the instantaneous tail current amplitude to the maximal amplitude of the instantaneous tail current. The data were fit with a single Boltzmann equation with the following parameters: WT (filled symbols), $V 1 / 2=-31.3 \mathrm{mV}, k=19.7 \mathrm{mV}, n=19 ; \mathrm{R} 327 \mathrm{H}$ (open symbols), $V 1 / 2=-96.2 \mathrm{mV}, k=19.5 \mathrm{mV}, n=11 . D$, Shown is the voltage dependence of activation time constant derived from a single-exponential fit of WT (filled symbols, $n=17$ ) and R327H (open symbols, $n=10$ ) current traces. $E$, Mg ${ }^{2+}$ slows activation kinetics of both WT and RH channels. Current traces of WT (left) and R327H (right) channels at 0 versus $5 \mathrm{~mm} \mathrm{Mg}^{2+}$; traces were obtained on the same cell in response to the test voltage of $+40 \mathrm{mV} . \boldsymbol{F}$, Left, $G / G_{\max }$ of WT and R327H mutant channels at different extracellular $\mathrm{Mg}^{2+}$. The data were fit with a Boltzmann equation. Filled squares, WT with $0 \mathrm{~mm} \mathrm{Mg}{ }^{2+}, V^{1} / 2=-51.5$ $\mathrm{mV}, k=16.8 \mathrm{mV}, n=6$; filled triangles, WT with $5 \mathrm{~mm} \mathrm{Mg}{ }^{2+}, V^{1} / 2=-12.5 \mathrm{mV}, k=17.1 \mathrm{mV}, n=3$; open squares, R327H with $0 \mathrm{~mm} \mathrm{Mg}^{2+}, V 1 / 2=-128.1 \mathrm{mV}, k=14.2 \mathrm{mV}, n=5 ;$ open triangles, R327H with $5 \mathrm{~mm} \mathrm{Mg}{ }^{2+}, V 1 / 2=-58.1 \mathrm{mV}, k=15.7 \mathrm{mV}, n=3 . F$, Right, The difference between $V^{1} / 2$ of WT and R327H channel expressed as a function of extracellular Mg ${ }^{2+}$. With the increase of $\mathrm{Mg}^{2+}$ concentration, the difference of $V^{1} / 2$ between WT and R327H became smaller.

\section{Voltage-clamp analysis}

To functionally assess whether these ionic interactions between Arg327 and negatively charged residues contribute to the channel gating, we conducted voltage-clamp experiments to study the activation of WT and R327H Kv10.2 channels. At $1 \mathrm{mM} \mathrm{Mg}^{2+}$ levels, voltage-clamp analysis showed that WT Kv10.2 current begins to activate at membrane voltages positive to $-110 \mathrm{mV}$ and reached half-maximal activation $\left(V_{1 / 2}\right)$ at $-31.5 \pm 1.7 \mathrm{mV}(n=$ 19; Fig. $3 A, C)$. The $\mathrm{R} 327 \mathrm{H}$ mutant channel was already active at $-140 \mathrm{mV}$ and reached $V_{1 / 2}$ at $-106.6 \pm 3.8 \mathrm{mV}(n=11$; Fig.
$3 B, C)$, which was significantly different from the $V_{1 / 2}$ of WT channel $(p<0.001)$. The slope of the Boltzmann curve was not different between WT $(20.7 \pm 0.5, n=19)$ and R327H (20.6 \pm $2.2, n=11)$ channels $(p>0.05)$. The maximum conductance of WT channel was $4.9 \pm 1.0 \mathrm{nS}(\mathrm{n}=19)$ and for the R327H channel was $5.6 \pm 2.3 \mathrm{nS}(n=11, p>0.05)$, indicating that $\mathrm{R} 327 \mathrm{H}$ mutation does not affect the functional expression of the channel.

To assess the kinetics of activation, the rising phase of both WT and R327H current, excluding an initial $10 \mathrm{~ms}$, was fitted with a single-exponential function. Activation kinetics of the mu- 
tant channel were significantly accelerated at voltages more negative than $20 \mathrm{mV}$, with a maximal difference at -60 to $-70 \mathrm{mV}$, a membrane voltage close to resting potential of most CNS neurons (Fig. 3D). Together, these data show that the R327H mutation enhances Kv10.2 channel activation and accelerates its activation kinetics at a wide range of physiological membrane voltages. These results indicate that $\mathrm{R} 327 \mathrm{H}$ mutation makes the channel easy to open and produces a gain-of-function phenotype of the Kv10.2 channel, consistent with the multistate structural modeling results.

It has been reported previously that extracellularly applied $\mathrm{Mg}^{2+}$ slows activation kinetics and depolarizes steady-state activation of EAG channels through binding to the residues at the outer VSD (Terlau et al., 1996; Silverman et al., 2000, 2004; Schonherr et al., 2002; Zhang et al., 2009). Therefore, it could be possible that the hyperpolarizing shift seen in $\mathrm{R} 327 \mathrm{H}$ mutation might partially arise from interference with the $\mathrm{Mg}^{2+}$ effects on channel activation via the structural changes caused by this mutation. To test this hypothesis, we recorded Kv10.2 activation at two different concentrations (0 and $5 \mathrm{~mm}$ ) of extracellular $\left[\mathrm{Mg}^{2+}\right]$.

Consistent with the previous results on channel steady-state activation, $\mathrm{Mg}^{2+}$ slowed activation kinetics of both WT and R327H channels (Fig. 3E). Moreover, we found that removal of extracellular $\mathrm{Mg}^{2+}$ resulted in a hyperpolarizing shift of steadystate activation of both WT and R327H channels: the Boltzmann fit of the channel activation in $0 \mathrm{mM} \mathrm{Mg}^{2+}$ had the following parameters: $V^{1 / 2}=-52.9 \pm 1.6 \mathrm{mV}(\mathrm{WT}, n=6)$ and $V^{1 / 2}=$ $-127.8 \pm 2.9 \mathrm{mV}(\mathrm{R} 327 \mathrm{H}, n=5), p<0.001 ; k=17.6 \pm 1.3 \mathrm{mV}$ (WT, $n=6) ; k=13.2 \pm 2.3 \mathrm{mV}(\mathrm{R} 327 \mathrm{H}, n=5), p>0.05$ (Fig. $3 F)$. In contrast, elevated $\mathrm{Mg}^{2+}$ resulted in a depolarizing shift of the channel steady-state activation. With $5 \mathrm{~mm} \mathrm{Mg}^{2+}$, steadystate activation curves were as follows: $V^{1 / 2}=-10.7 \pm 1.0 \mathrm{mV}$ (WT, $n=3$ ) and $V^{1 / 2}=-58.6 \pm 3.3 \mathrm{mV}(\mathrm{R} 327 \mathrm{H}, n=3), p<$ $0.01 ; k=20.6 \pm 0.2 \mathrm{mV}(\mathrm{WT}, n=3)$ and $k=18.1 \pm 2.0 \mathrm{mV}$ $(\mathrm{R} 327 \mathrm{H}, n=3), p>0.05$ (Fig. 3F). These data are consistent with previous reports and indicate that, for both WT and $\mathrm{R} 327 \mathrm{H}$ channels, the presence of $\mathrm{Mg}^{2+}$ was able to shift the activation $V^{1} / 2$ in a depolarizing direction.

As shown in Figure $3 F$, left, the shift of activation $\left(\Delta V^{1 / 2}\right)$ in 5 $\mathrm{mM} \mathrm{Mg}^{2+}$ compared with $0 \mathrm{mM} \mathrm{Mg}{ }^{2+}$ for the R327H mutant channel is significantly larger than that in $\mathrm{WT}(\sim 70 \mathrm{vs} \sim 40 \mathrm{mV})$. Moreover, Figuew $3 F$, right, shows that the difference between activation $V^{1 / 2}$ of WT and $\mathrm{R} 327 \mathrm{H}$ channel $\left(\Delta V^{1 / 2} \mathrm{WT} / \mathrm{RH}\right)$ became bigger as the $\mathrm{Mg}^{2+}$ concentration decreased. Both of these findings indicate that the enhanced activation seen in $\mathrm{R} 327 \mathrm{H}$ mutation is not likely attributable to reduced $\mathrm{Mg}^{2+}$ sensitivity of the mutant channel. Because $\mathrm{Mg}^{2+}$ sensitivity is mainly mediated by the outer voltage sensor, our data suggest that the outer voltage sensor probably has a normal conformation in the R327H mutant channel, consistent with our argument that the R327H mutation mainly effects inner voltage sensor charge pairing.

\section{Discussion}

In this study, we report structural and functional analyses of the Kv10.2 Arg327 residue and mutated R327H using a novel multistate structural modeling and voltage clamp. The R327H mutation, identified by whole exome sequencing in a patient with epileptic encephalopathy (Veeramah et al., 2013), is the first mutation of the KCNH5 gene associated with neurological disease. Taking advantage of Kv channel crystal structures and recent molecular dynamic simulations of $\mathrm{Kv}$ channel, we performed detailed analysis of the interaction of the WT Arg327 and the substituted $\mathrm{R} 327 \mathrm{H}$ with surrounding residues during channel gating. Our results suggest that the Arg327 residue, a critical positively charged residue known as R2 of S4 helix within the VSD, has strong interactions with negatively charged residues in the resting state and other intermediate states transiting into or out of the resting state. The $\mathrm{R} 327 \mathrm{H}$ mutation resulted in reduced size of the residue 327 side chain and a loss of positive charges, leading to weaker interaction of residue 327 with negatively charged residues in the resting state, thus making the channel easier to open.

Kv10.2 channel is related to Drosophila EAG, Eag-related gene (Erg), and Eag-like $\mathrm{K}^{+}$channel (Elk) $\mathrm{K}^{+}$channel subfamilies, which correspond to the mammalian Kv10, Kv11, and Kv12 channel subfamilies, respectively (Ganetzky et al., 1999; Wulff et al., 2009). The Drosophila Erg $\mathrm{K}^{+}$channel is encoded by the seizure locus, and the mutations in Erg cause a temperatureinduced hyperactivity and paralytic phenotype (Titus et al., 1997; Wang et al., 1997). Additionally, a recent study reported that the Kv12.2 (Elk2) channel knock-out causes persistent neuronal hyperexcitability and spontaneous seizures in mice (Zhang et al., 2010). However, until recently, a role for EAG channels in seizures was only inferred by analogy to the other $\mathrm{K}^{+}$channel subfamilies. Our identification of the first Kv10.2 mutation associated with human disease, together with the structure-andfunction study we report here, provide compelling evidence for a role of Kv10.2 channel in human neurological disease.

Kv10.1 and Kv10.2 channels have been associated previously with cancer (Camacho, 2006; Hemmerlein et al., 2006; Mello de Queiroz et al., 2006; Stühmer et al., 2006; Huang et al., 2012), but their functional roles in the nervous system and neurological diseases have not been revealed. Consistent with multiple neurodevelopmental deficits in the patient carrying the Kv10.2 R327H mutation, including seizure and multifocal EEG spikes that were almost continuous during sleep, severe language delay, autism, and hypotonia (Veeramah et al., 2013), Kv10.2 has been shown to be expressed in multiple areas of the brain (Saganich et al., 1999; Ludwig et al., 2000; Ju and Wray, 2002; Schonherr et al., 2002). Based on our structural and functional analyses, the Kv10.2 $\mathrm{R} 327 \mathrm{H}$ mutation appears to confer gain-of-function changes on the channel.

Gain-of-function $\mathrm{K}^{+}$channel mutations associated with epilepsy have been found previously in large-conductance calciumsensitive potassium channels (Du et al., 2005; N'Gouemo, 2011). These mutations have been suggested to lead to increased neuronal excitability and epilepsy via alternative mechanisms depending on the levels and expression pattern of the mutant channels in different types of neurons: (1) mutant channels are dominant in excitatory neurons, and the gain-of-function $\mathrm{K}^{+}$channel mutations may enhance the afterhyperpolarization of the action potential, leading to faster repriming (removal of inactivation) of sodium channels, thus allowing excitatory neurons to fire at a higher frequency; (2) enhancement of activity of mutant $\mathrm{K}^{+}$channel within very negative voltage domains might also lead to additional hyperpolarization and the activation of hyperpolarization-activated cation current (e.g., $I_{\mathrm{h}}$ ), generating secondary depolarization; and (3) mutant channels are dominant in inhibitory neurons, and the gain-offunction $\mathrm{K}^{+}$channel mutation may increase basal $\mathrm{K}^{+}$conductance, reduce input resistance of the cellular membrane, and impair the firing of inhibitory interneurons, thus relieving inhibition on a neuronal network. The last mechanism has been suggested previously for loss-of-function mutations of voltage-gated sodium channel Nav1.1 in severe childhood epilepsy (Catterall et al., 2010). Interestingly, loss-of-function changes in potassium channels are also seen in epilepsy, in- 
cluding Kv7 (KCNQ) channel mutations of benign familial neonatal convulsions (Lerche et al., 2001; Cooper, 2012; Miceli et al., 2013), suggesting that both gain-of-function and loss-of-function $\mathrm{Kv}$ channel mutations may contribute to epilepsy, probably via altering excitability of different neuronal types. Kv10.2 has been found in cortical layer IV, which contains both excitatory and inhibitory interneurons (Saganich et al., 1999). A finely tuned and cell-specific balance of potassium channel activities seems to be critical for neurons to maintain normal functions.

Mutagenesis studies of positively charged residues in S4 helix of a number of $\mathrm{Kv}$ channels have been reported previously (Panaghie and Abbott, 2007). In particular, it has been found that mutations of $\mathrm{R} 2$ residues cause a dramatic loss of voltagedependent gating in Kv7.2 and Kv7.4 channels, leading to apparently constitutively activated channels at testing potentials from -120 to $40 \mathrm{mV}$ (Miceli et al., 2008, 2012). Our structural analysis indicates that R2 (Arg327 of Kv10.2) interacts with many negatively charged residues during channel gating into and out of resting states, and the mutation of R2 (R327H) weakens these interaction, destabilizing the resting state so that the channel more readily opens. Voltage-clamp studies are consistent with this hypothesis and show that the mutation shifts channel activation $V^{1 / 2}$ of $\sim 70 \mathrm{mV}$ in a hyperpolarizing direction, reinforcing the essential role of the $\mathrm{R} 2$ residue in stabilization of the channel resting state. At first glance, the $\mathrm{R} 327 \mathrm{H}$ mutation reported herein retains voltage sensitivity of the channel, which is in contrast to mutations of R2 studied in the Kv7 channels (Miceli et al., 2008, 2012). However, we cannot rule out the possibility that a very strong hyperpolarizing shift in voltage dependence of activation mediated by R2Q mutant of Kv7.2 and Kv7.4 might make the mutant channels appear constitutively active, resulting in voltage independence seen in the tested voltage range $(-120$ to $40 \mathrm{mV})$ but that voltage dependence might be retained at membrane potentials more negative than $-120 \mathrm{mV}$. If this prediction turns out to be correct, then our model is likely to be generalizable for many additional voltage-gated ion channels.

Interactions between positively charged residues in S4 and negatively charged residues in S1-S3 helices of VSD have been implicated in the gating of both voltage-gated sodium and potassium channels (Tao et al., 2010; Wu et al., 2010; DeCaen et al., 2011; Delemotte et al., 2011; Pless et al., 2011; Vargas et al., 2012; Yarov-Yarovoy et al., 2012). The present results, based on a naturally occurring mutation found in a patient with neurological disease, indicate that the $\mathrm{R} 2$ residue of the Kv10.2 channel interacts with negatively charged residues in S0-S3 helices in different conformational states during channel gating. Disruption of this interaction, in this case by substitution of the Arg327 with the histidine residue, destabilizes the closed state of the channel. Thus, the R2 (Arg327) residue of the WT channel appears to play a critical role in stabilizing the channel closed state.

\section{References}

Arnold K, Bordoli L, Kopp J, Schwede T (2006) The SWISS-MODEL workspace: a web-based environment for protein structure homology modelling. Bioinformatics 22:195-201. CrossRef Medline

Bordoli L, Kiefer F, Arnold K, Benkert P, Battey J, Schwede T (2009) Protein structure homology modeling using SWISS-MODEL workspace. Nat Protoc 4:1-13. CrossRef Medline

Camacho J (2006) Ether a go-go potassium channels and cancer. Cancer Lett 233:1-9. CrossRef Medline
Catterall WA, Kalume F, Oakley JC (2010) NaV1.1 channels and epilepsy. J Physiol 588:1849-1859. CrossRef Medline

Cooper EC (2012) Potassium channels (including KCNQ) and epilepsy. In: Jasper's basic mechanisms of the epilepsies, Ed 4 (Noebels JL, Avoli M, Rogawski MA, Olsen RW, Delgado-Escueta AV, eds). Bethesda, MD: Oxford University Press.

Cummins TR, Aglieco F, Renganathan M, Herzog RI, Dib-Hajj SD, Waxman SG (2001) Nav1.3 sodium channels: rapid repriming and slow closedstate inactivation display quantitative differences after expression in a mammalian cell line and in spinal sensory neurons. J Neurosci 21:59525961. Medline

DeCaen PG, Yarov-Yarovoy V, Scheuer T, Catterall WA (2011) Gating charge interactions with the $\mathrm{S} 1$ segment during activation of a $\mathrm{Na}+$ channel voltage sensor. Proc Natl Acad Sci U S A 108:18825-18830. CrossRef Medline

Delemotte L, Tarek M, Klein ML, Amaral C, Treptow W (2011) Intermediate states of the Kv1.2 voltage sensor from atomistic molecular dynamics simulations. Proc Natl Acad Sci U S A 108:6109-6114. CrossRef Medline

Du W, Bautista JF, Yang H, Diez-Sampedro A, You SA, Wang L, Kotagal P, Lüders HO, Shi J, Cui J, Richerson GB, Wang QK (2005) Calciumsensitive potassium channelopathy in human epilepsy and paroxysmal movement disorder. Nat Genet 37:733-738. CrossRef Medline

Ganetzky B, Robertson GA, Wilson GF, Trudeau MC, Titus SA (1999) The eag family of $\mathrm{K}^{+}$channels in Drosophila and mammals. Ann N Y Acad Sci 868:356-369. CrossRef Medline

Hemmerlein B, Weseloh RM, Mello de Queiroz F, Knötgen H, Sánchez A, Rubio ME, Martin S, Schliephacke T, Jenke M, Heinz-Joachim-Radzun, Stühmer W, Pardo LA (2006) Overexpression of Eagl potassium channels in clinical tumours. Mol Cancer 5:41. CrossRef Medline

Huang X, Dubuc AM, Hashizume R, Berg J, He Y, Wang J, Chiang C, Cooper MK, Northcott PA, Taylor MD, Barnes MJ, Tihan T, Chen J, Hackett CS, Weiss WA, James CD, Rowitch DH, Shuman MA, Jan YN, Jan LY (2012) Voltage-gated potassium channel EAG2 controls mitotic entry and tumor growth in medulloblastoma via regulating cell volume dynamics. Genes Dev 26:1780-1796. CrossRef Medline

Jensen MØ, Jogini V, Borhani DW, Leffler AE, Dror RO, Shaw DE (2012) Mechanism of voltage gating in potassium channels. Science 336:229233. CrossRef Medline

Ju M, Wray D (2002) Molecular identification and characterisation of the human eag2 potassium channel. FEBS Lett 524:204-210. CrossRef Medline

Lee SY, Banerjee A, MacKinnon R (2009) Two separate interfaces between the voltage sensor and pore are required for the function of voltagedependent $\mathrm{K}^{+}$channels. PLoS Biol 7:e47. CrossRef Medline

Lerche H, Jurkat-Rott K, Lehmann-Horn F (2001) Ion channels and epilepsy. Am J Med Genet 106:146-159. CrossRef Medline

Long SB, Tao X, Campbell EB, MacKinnon R (2007) Atomic structure of a voltage-dependent $\mathrm{K}^{+}$channel in a lipid membrane-like environment. Nature 450:376-382. CrossRef Medline

Ludwig J, Weseloh R, Karschin C, Liu Q, Netzer R, Engeland B, Stansfeld C, Pongs O (2000) Cloning and functional expression of rat eag2, a new member of the ether-a-go-go family of potassium channels and comparison of its distribution with that of eag1. Mol Cell Neurosci 16:59-70. CrossRef Medline

Mello de Queiroz F, Suarez-Kurtz G, Stühmer W, Pardo LA (2006) Ether a go-go potassium channel expression in soft tissue sarcoma patients. Mol Cancer 5:42. CrossRef Medline

Miceli F, Soldovieri MV, Hernandez CC, Shapiro MS, Annunziato L, Taglialatela M (2008) Gating consequences of charge neutralization of arginine residues in the $\mathrm{S} 4$ segment of $\mathrm{K}(\mathrm{v}) 7.2$, an epilepsy-linked $\mathrm{K}^{+}$channel subunit. Biophys J 95:2254-2264. CrossRef Medline

Miceli F, Vargas E, Bezanilla F, Taglialatela M (2012) Gating currents from Kv7 channels carrying neuronal hyperexcitability mutations in the voltage-sensing domain. Biophys J 102:1372-1382. CrossRef Medline

Miceli F, Soldovieri MV, Ambrosino P, Barrese V, Migliore M, Cilio MR, Taglialatela M (2013) Genotype-phenotype correlations in neonatal epilepsies caused by mutations in the voltage sensor of $\mathrm{K}(\mathrm{v}) 7.2$ potassium channel subunits. Proc Natl Acad Sci U S A 110:4386-4391. CrossRef Medline

N'Gouemo P (2011) Targeting BK (big potassium) channels in epilepsy. Expert Opin Ther Targets 15:1283-1295. CrossRef Medline

Panaghie G, Abbott GW (2007) The role of S4 charges in voltage-dependent 
and voltage-independent KCNQ1 potassium channel complexes. J Gen Physiol 129:121-133. CrossRef Medline

Pathak MM, Yarov-Yarovoy V, Agarwal G, Roux B, Barth P, Kohout S, Tombola F, Isacoff EY (2007) Closing in on the resting state of the Shaker $\mathrm{K}^{+}$ channel. Neuron 56:124-140. CrossRef Medline

Pless SA, Galpin JD, Niciforovic AP, Ahern CA (2011) Contributions of counter-charge in a potassium channel voltage-sensor domain. Nat Chem Biol 7:617-623. CrossRef Medline

Saganich MJ, Vega-Saenz de Miera E, Nadal MS, Baker H, Coetzee WA, Rudy B (1999) Cloning of components of a novel subthreshold-activating $\mathrm{K}^{+}$ channel with a unique pattern of expression in the cerebral cortex. J Neurosci 19:10789-10802. Medline

Schönherr R, Gessner G, Löber K, Heinemann SH (2002) Functional distinction of human EAG1 and EAG2 potassium channels. FEBS Lett 514: 204-208. CrossRef Medline

Silverman WR, Tang CY, Mock AF, Huh KB, Papazian DM (2000) $\mathrm{Mg}^{2+}$ modulates voltage-dependent activation in ether-a-go-go potassium channels by binding between transmembrane segments S2 and S3. J Gen Physiol 116:663-678. CrossRef Medline

Silverman WR, Bannister JP, Papazian DM (2004) Binding site in eag voltage sensor accommodates a variety of ions and is accessible in closed channel. Biophys J 87:3110-3121. CrossRef Medline

Stühmer W, Alves F, Hartung F, Zientkowska M, Pardo LA (2006) Potassium channels as tumour markers. FEBS Lett 580:2850-2852. CrossRef Medline

Tao X, Lee A, Limapichat W, Dougherty DA, MacKinnon R (2010) A gating charge transfer center in voltage sensors. Science 328:67-73. CrossRef Medline

Terlau H, Ludwig J, Steffan R, Pongs O, Stühmer W, Heinemann SH (1996) Extracellular $\mathrm{Mg}^{2+}$ regulates activation of rat eag potassium channel. Pflugers Arch 432:301-312. CrossRef Medline

Titus SA, Warmke JW, Ganetzky B (1997) The Drosophila erg K ${ }^{+}$channel polypeptide is encoded by the seizure locus. J Neurosci 17:875-881. Medline

Vargas E, Yarov-Yarovoy V, Khalili-Araghi F, Catterall WA, Klein ML, Tarek M, Lindahl E, Schulten K, Perozo E, Bezanilla F, Roux B (2012) An emerging consensus on voltage-dependent gating from computational modeling and molecular dynamics simulations. J Gen Physiol 140:587594. CrossRef Medline
Veeramah KR, Johnstone L, Karafet TM, Wolf D, Sprissler R, Salogiannis J, Barth-Maron A, Greenberg ME, Stuhlmann T, Weinert S, Jentsch TJ, Pazzi M, Restifo LL, Talwar D, Erickson RP, Hammer MF (2013) Exome sequencing reveals new causal mutations in children with epileptic encephalopathies. Epilepsia 54:1270-1281. CrossRef Medline

Wang XJ, Reynolds ER, Déak P, Hall LM (1997) The seizure locus encodes the Drosophila homolog of the HERG potassium channel. J Neurosci 17:882-890. Medline

Wu D, Delaloye K, Zaydman MA, Nekouzadeh A, Rudy Y, Cui J (2010) State-dependent electrostatic interactions of S4 arginines with E1 in S2 during Kv7.1 activation. J Gen Physiol 135:595-606. CrossRef Medline

Wulff H, Castle NA, Pardo LA (2009) Voltage-gated potassium channels as therapeutic targets. Nat Rev Drug Discov 8:982-1001. CrossRef Medline

Yang Y, Shi W, Chen X, Cui N, Konduru AS, Shi Y, Trower TC, Zhang S, Jiang C (2011) Molecular basis and structural insight of vascular K(ATP) channel gating by S-glutathionylation. J Biol Chem 286:9298-9307. CrossRef Medline

Yang Y, Dib-Hajj SD, Zhang J, Zhang Y, Tyrrell L, Estacion M, Waxman SG (2012) Structural modeling and mutant cycle analysis predict pharmacoresponsiveness of a NaV1.7 mutant channel. Nat Commun 3:1186. CrossRef Medline

Yang Y, Estacion M, Dib-Hajj SD, Waxman SG (2013) Molecular architecture of a sodium channel S6 helix: radial tuning of the voltage-gated sodium channel 1.7 activation gate. J Biol Chem 288:13741-13747. CrossRef Medline

Yarov-Yarovoy V, DeCaen PG, Westenbroek RE, Pan CY, Scheuer T, Baker D, Catterall WA (2012) Structural basis for gating charge movement in the voltage sensor of a sodium channel. Proc Natl Acad Sci U S A 109: E93-E102. CrossRef Medline

Zhang X, Bursulaya B, Lee CC, Chen B, Pivaroff K, Jegla T (2009) Divalent cations slow activation of EAG family $\mathrm{K}^{+}$channels through direct binding to S4. Biophys J 97:110-120. CrossRef Medline

Zhang X, Bertaso F, Yoo JW, Baumgärtel K, Clancy SM, Lee V, Cienfuegos C, Wilmot C, Avis J, Hunyh T, Daguia C, Schmedt C, Noebels J, Jegla T (2010) Deletion of the potassium channel Kv12.2 causes hippocampal hyperexcitability and epilepsy. Nat Neurosci 13:1056-1058. CrossRef Medline 